Article

\title{
Phosphorus Distribution in Soils from Australian Dairy and Beef Rearing Pastoral Systems
}

\author{
Samuel B. Adeloju ${ }^{1, *}$, Benjamin Webb ${ }^{1,2}$ and Ronald Smernik ${ }^{3}$ \\ 1 NanoScience and Sensor Technology Research Group, School of Chemistry, Monash University, Clayton, \\ Victoria 3800, Australia \\ 2 School of Applied and Biomedical Sciences, Faculty of Science and Technology, \\ Federation University Australia, Gippsland Campus, Churchill, Victoria 3842, Australia; \\ benjamin.webb@federation.edu.au \\ 3 School of Agriculture, Food and Wine, University of Adelaide, Waite Campus, Urrbrae SA 5064, Australia; \\ ronald.smernik@adelaide.edu.au \\ * Correspondence: Sam.Adeloju@monash.edu; Tel.: +61-3-9905-4555; Fax: +61-3-9905-4597
}

Academic Editor: Mikio Nakamura

Received: 14 November 2015; Accepted: 15 January 2016; Published: 25 January 2016

\begin{abstract}
The influence of soil type and management practices on P distribution in soils from Australian dairy and beef rearing pastoral systems has been investigated by chemical measurements and phosphorus-31 $\left({ }^{31} \mathrm{P}\right)$ nuclear magnetic resonance (NMR) spectroscopy. The amount and forms of $\mathrm{P}$ within the soil profile varied with soil type, with the acidic red Ferrosols containing relatively high orthophosphate concentrations, averaging $72.2 \%$ compared with $66.8 \%$ for Dermosols, under similar management conditions. Soil from Sodosol sites which received less fertiliser P addition had the lowest orthophosphate concentration with only $57.6 \%$. In contrast, relatively high proportions of organic $\mathrm{P}$ were found in soil samples from unfertilised Sodosol sites. On average, soil from Sodosol sites contained $37.5 \%$ organic $\mathrm{P}$ (combined monoester $\mathrm{P}$ and diester $\mathrm{P}$ ), while those from Dermosol and Ferrosol sites contained $31.7 \%$ and $25.8 \%$, respectively. Of these, the highest monoester phosphate proportions of $44.6 \%$ (site M3) and $46.4 \%$ (site M4) were found in Sodosol sites with no recent P inputs, but the highest proportion of diester phosphate (5.7\%) was found in an unclassified grey sandy loam Dermosol. The higher organic P concentrations in soil from Sodosol sites may be associated with more regular moisture input from both rainfall and boarder-check (flood) irrigation. The highest level of pyrophosphate $(8.5 \%)$ was also found in a grey/yellow Sodosol. Overall, the results indicate that $\mathrm{P}$ speciation in the Australian soils is strongly influenced by soil type, fertiliser P application rate and timing, and moisture variations.
\end{abstract}

Keywords: Phosphorus; ${ }^{31}$ P NMR spectroscopy; soil; organic P; cultivation; irrigation

\section{Introduction}

Phosphorus (P) exists in soils in both inorganic and organic forms [1,2]. Many agricultural areas have relatively high soil total $\mathrm{P}$ concentrations compared to background environmental levels [3] However, these high concentrations are often sub-optimal for agricultural practices, as most of the soil $\mathrm{P}$ is not readily available to plants because it is bound in insoluble inorganic and organic forms, such as calcium, iron and aluminum phosphate, inositol hexakisphosphate, and phytate. The deficit of available $P$ is often treated through the addition of inorganic $P$ fertilisers. A proportion of this is also converted into insoluble forms $[4,5]$, which accumulate, raising overall soil $\mathrm{P}$ concentrations.

The organic P content of soil depends on a number of factors, including soil drainage, soil $\mathrm{pH}$, the inorganic content of parent material and cultivation [6]. As a consequence, the organic $P$ fraction of soils varies significantly, generally representing between $20 \%$ and $80 \%$ of total soil P [6-8]. Pasture 
soils tend to contain a higher proportion of organic P than cultivated soils [9]. Some of the "available" organic $\mathrm{P}$ forms play important role in biological cycling of $\mathrm{P}$ in soils, however the dynamics of organic $\mathrm{P}$ are not completely understood and require further investigation [10,11].

Organic $\mathrm{P}$ determinations in soil can be difficult due to extraction, separation and detection problems [12]. First identified in $1940[13,14]$, phytate $\left(\mathrm{C}_{6} \mathrm{H}_{6} \mathrm{Ca}_{6} \mathrm{O}_{24} \mathrm{P}_{6}\right.$ as a calcium salt) has been considered the abundant organic $P$ form $[6,11,15]$, representing up to $50 \%$ of all soil organic $P[6,16,17]$. However, an investigation by Smernik and Dougherty [18] involving phytate spiking, has indicated that this organic $\mathrm{P}$ may have been previously overestimated due to misassignment of resonances in ${ }^{31} \mathrm{P}$ NMR spectra. Their study showed that phytate contributed $<5 \%$ and $<3 \%$ of organic $\mathrm{P}$ and total $\mathrm{P}$, respectively, in the four Australian grazing soils analysed.

Many methods have been used to extract organic $\mathrm{P}$, including base extraction, chromatographic isolation and acid or base hydrolysis [18-22]. More recently, phosphorus-31 $\left({ }^{31} \mathrm{P}\right)$ nuclear magnetic resonance (NMR) spectroscopy has been adopted as it removes many limiting factors of these chromatographic methods [12]. Phosphorus is particularly amenable to NMR analysis because NMR-active ${ }^{31} \mathrm{P}$ is the only $\mathrm{P}$ isotope found naturally. The main advantage of NMR is that it has the potential to be able to detect and quantify all $\mathrm{P}$ species simultaneously [23].

First used for soil characterisation in 1980 [24], ${ }^{31} \mathrm{P}$ NMR spectroscopy has been used for both qualitative and quantitative estimates of both organic and inorganic soil P compounds [2,25]. The use of ${ }^{31} \mathrm{P}$ NMR spectroscopy enables quantification of many phosphate compounds, including inorganic orthophosphate $\left(\mathrm{PO}_{4}{ }^{3-}\right)$, polyphosphate $\left(\mathrm{P}_{n} \mathrm{O}_{3 n+1}{ }^{(n+2)-}\right)$ and pyrophosphate $\left(\mathrm{P}_{2} \mathrm{O}_{7}{ }^{4-}\right)$, organic orthophosphate monoesters $\left(\mathrm{RPO}_{4}{ }^{2-}\right)$ and diesters $\left(\mathrm{R}_{2} \mathrm{PO}_{4}{ }^{-}\right)$, as well as some specific organic $\mathrm{P}$ compounds $[8,11,25,26]$. Of the organic compounds, monoesters are usually the principal form found in soil [6]. Monoester phosphates combine with metal ions, like $\mathrm{Fe}$, to produce moderately labile insoluble complexes $[16,27,28]$. However, it has recently been reported that monoesters such as Inositolhexaphosphate isomers are often dominating and they do not produce moderately labile insoluble complexes, but are strongly bound to the soil solid phase [29]. Organic diesters are found in relatively small concentrations compared to monoesters. Diester phosphates are considered more labile than monoester phosphate and are generally more accessible to attack by soil microbes, which in combination contributes to lower concentrations in soil [27,28].

A study comparing soil extraction procedures for ${ }^{31} \mathrm{P}$ NMR spectroscopy reported that the highest total $\mathrm{P}$ recovery and the greatest diversity of $\mathrm{P}$ forms were achieved using a combined $\mathrm{NaOH}$ and EDTA solution [25]. A method for the extraction and subsequent quantification of organic $\mathrm{P}$ using ${ }^{31} \mathrm{P}$ NMR spectroscopy coupled with a NaOH-EDTA extraction was also reported [15]. The addition of EDTA enables better characterisation of organic $\mathrm{P}$ than possible in $\mathrm{NaOH}$ extractions [25]. Due to the relative ease of the method, ${ }^{31} \mathrm{P}$ NMR analysis of $\mathrm{NaOH}$-EDTA extracts has been widely accepted as the preferred technique for organic $P$ measurement $[8,11,18]$.

In this study, the surface soil P components of soil samples collected from dairy and beef rearing pastoral systems from two areas in the Gippsland region (south-eastern Victoria, Australia) are measured by chemical methods and ${ }^{31} \mathrm{P}$ NMR spectroscopy, and comparison is made to: (a) identify factors influencing the concentrations of organic and total P in different Australian soils; (b) establish if there are differences between soil P components of multiple pastoral systems; (c) investigate if and how $\mathrm{P}$ components vary between two agricultural areas; and (d) identify how physical factors, such as moisture, soil $\mathrm{pH}$, slope and elevation, affect $\mathrm{P}$ composition and concentrations, particularly the organic $\mathrm{P}$, of different soils.

\section{Materials and Methods}

\subsection{Sampling Site Descriptions}

Soil samples were collected from selected agricultural sites situated in two areas in the Gippsland region of south-east Victoria, near Maffra and Warragul (Figure 1). These areas were selected as 
geographically close agricultural areas (approximately $120 \mathrm{~km}$ range) with varying agricultural management practices, particularly irrigation application. The average annual rainfall for the two areas is $582 \mathrm{~mm}$ for Maffra and $1021 \mathrm{~mm}$ for Warragul. Average ambient air temperatures range from $8.4^{\circ} \mathrm{C}$ (min) to $19.2{ }^{\circ} \mathrm{C}(\max )$ for Warragul and $8.1{ }^{\circ} \mathrm{C}(\min )$ to $20.0{ }^{\circ} \mathrm{C}(\max )$ for Maffra. Rainfall and temperature may be variable between individual locations within each of these areas.

All sites of the Maffra area receive irrigation as part of the Macalister Irrigation District (MID). On the other hand, the Warragul area is predominantly a rain-fed system, and none of the soils from the Warragul area were irrigated. The number of irrigations applied to sampling sites of the Maffra area varied. Based on available information, irrigations for the Macalister Research Farm $\left(38^{\circ} 00^{\prime} \mathrm{S}\right.$ $146^{\circ} 54^{\prime} \mathrm{E}$ ), a dairy farm situated in the MID, typically vary between 10 and 16 per annum. Stocking rates varied between agricultural areas, ranging between 1.8 to 2.8 cattle ha $^{-1}$ for the Warragul area (Laidlaw, personal communication, 2009) and between 3.0 to 4.3 cattle ha $^{-1}$ (Tyndal, personal communication, 2009) for the Maffra area. The higher stocking rates in the Maffra area can be attributed to availability of irrigation water during the dryer periods of the year.

Dairy production pastures were mainly grazed with Friesian cattle, however milking herds often contained some Jersey cattle. Beef production cattle herds were predominantly of Angus or Hereford cattle. Selected sites were not grazed for at least one week prior to sampling. As the sites were grazed, nutrients were returned to soil unhindered through faeces and urine. Urine of ruminants generally only has trace amounts of $\mathrm{P}$, however this does increase as $\mathrm{P}$ intake increases [30,31]. Livestock faeces have been shown to have an increased inorganic and organic $P$ content compared to the ingested pasture [32]. Hence, cattle dung contributes to localised, high intensity inputs of nutrients including $\mathrm{P}[33,34]$. The overall $\mathrm{P}$ contribution and speciation from cattle faeces varies depending on a number of factors including water regime [35] and weather/seasonal conditions [36]. To minimise possible effects on the results obtained in this study, areas with excreted wastes were carefully avoided during soil sampling, and large number of soil cores $(200+)$ were bulked to minimise contribution from animal excretions.

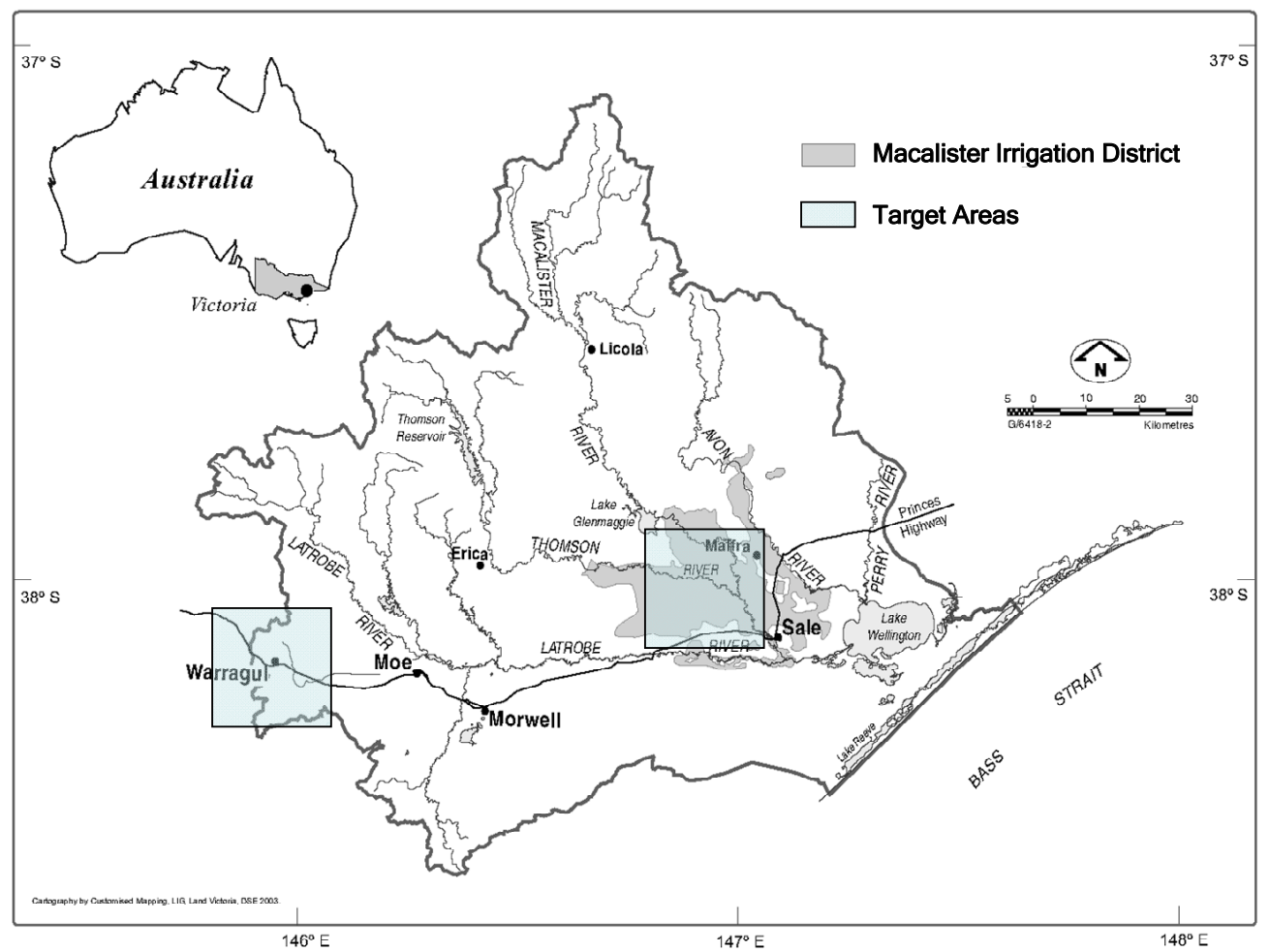

Figure 1. Selected sampling areas within the Gippsland region of south-eastern Victoria. Adapted from Nash [37]. 
The locations sampled carried permanent pastures which were predominantly perennial ryegrass (Lolium perenne), white clover (Trifolium repens) and contained assorted invasive species, particularly dock (Rumex spp.), cape weed (Arctotheca calendula), marshmallow weed (Malva parviflora) and distichum (Paspalum paspaloides). Pastures were maintained with the addition of varying rates of inorganic fertiliser blends which included P. Available information indicated that the sampled sites received no cultivation and/or cropping for at least 10 years prior to sampling. The exception was site M6, which was laser graded six years prior to sampling. Laser-grading involved cultivation using a disk plough followed by minor cutting and filling as the bay had previously been formed ( $>20$ years prior) [38].

\subsection{Soil Characterisation}

A total of fourteen sites were sampled, seven from each of the two sampling areas. Soils were classified using the Australian soil classification system [39]. The seven sites of the Warragul area represented three different soil types: grey clay loam Dermosols (sites W1, W2 and W6), acidic red clay loam Ferrosols (sites W3, W4 and W5), and an unclassified sandy clay loam (site W7), which was possibly derived from a grey clay loam Dermosol, as the sampled area was dominated by these soils [40]. The seven sites in the Maffra area also represented three soil types: a grey/red clay loam Sodosol (sites M1, M2, M3 and M4), a grey/yellow clay loam Sodosol (site M5) and a grey clay loam Sodosol (sites M6 and M7) [41].

\subsection{Sample Collection and Preparation}

In late April and May 2007, at least 200 soil cores were collected from each sampling site to a depth of $20 \mathrm{~mm}$ using a grid pattern with three parallel rows. The total area sampled in this way equated to between 9000 and $12,000 \mathrm{~m}^{2}$. Soil cores were bulked to provide composite samples for each location. Samples were stored $\left(4^{\circ} \mathrm{C}\right)$ in polyurethane bags and transported to the laboratory. The bulked soils were dried $\left(40^{\circ} \mathrm{C}\right)$, ground and passed through a $2 \mathrm{~mm}$ sieve. Samples were stored in polyethylene containers at $c a .20^{\circ} \mathrm{C}$ prior to analysis.

\subsection{Sample Analyses}

\subsubsection{Standard Soil Analyses}

Soils were analysed for $\mathrm{pH}$ in both water $\left(\mathrm{pH}_{\mathrm{W}}\right)$ and $0.01 \mathrm{M}$ calcium chloride $\left(\mathrm{pH}_{\mathrm{Ca}}\right)$, electrical conductivity (EC), Olsen P and Colwell P using standard methods [42]. The $\mathrm{pH}$ and EC measurements each used a 1:5 soil to solute ratio and $\mathrm{pH}$ was measured following shaking for $1 \mathrm{~h}$. Colwell $\mathrm{P}$ and Olsen $\mathrm{P}$ measurements are described as agronomic soil testing procedures, as usually considered. Colwell $\mathrm{P}$ was determined by using a 1:100 soil to $0.5 \mathrm{M}$ sodium bicarbonate $\left(\mathrm{NaHCO}_{3}\right)$ solution ratio at $\mathrm{pH} 8.5$ with $16 \mathrm{~h}$ extraction. On the other hand, Olsen $\mathrm{P}$ was determined by using a 1:20 soil to $0.5 \mathrm{M} \mathrm{NaHCO}_{3}$ solution ( $\mathrm{pH} 8.5$ ) ratio with $30 \mathrm{~min}$ extraction. In effect, due to its shorter extraction time, Olsen P measures the freely (plant) available P in alkaline soil while Colwell used longer extraction time to detect both freely available $\mathrm{P}$ and structurally bound $\mathrm{P}$ as an estimate of the available phosphorus reserves. For this reason, the measured $\mathrm{P}$ value for the latter will tend to be higher than for the former.

Environmental or intensity soil $\mathrm{P}$ tests were also conducted, with water and calcium chloride extraction. Water extractable $\mathrm{P}$ (WEP) was measured after a $1 \mathrm{~h}$ extraction using a 1:10 ratio of soil to deionised water, followed by filtration through a $0.45-\mu \mathrm{m}$ Biolab (Atlanta, GA, USA) polyvinylidene difluoride (PVDF) syringe filter membrane. Calcium chloride extractable $\mathrm{P}$ (CCEP) was measured after a $1 \mathrm{~h}$ extraction using a 1:10 ratio of soil to $0.01 \mathrm{M} \mathrm{CaCl}_{2}$ solution followed by filtration through a Whatman (Maidestone, Kent, UK) \#2 filter paper. 


\subsubsection{Total Soil Phosphorus Determination}

Soil samples $(0.3 \mathrm{~g})$ were accurately weighed into a $100 \mathrm{~mL}$ Erlenmeyer flask and $10 \mathrm{~mL}$ of $\mathrm{H}_{2} \mathrm{SO}_{4}$ $(98 \%)$ was added to the soil in a fume hood, with a glass funnel placed into the neck of the flask. The mixture was heated to approximately $160^{\circ} \mathrm{C}$ until sulphite fumes occurred. The mixture was reduced by evaporation to approximately $2 \mathrm{~mL}$ and then allowed to cool for $3 \mathrm{~min}$. Four further $1 \mathrm{~mL}$ aliquots of $\mathrm{H}_{2} \mathrm{SO}_{4}$ were added sequentially, with each followed by reduction of volume to $2 \mathrm{~mL}$ by evaporation and cooling. Following the final addition, the mixture was heated $\left(160^{\circ} \mathrm{C}\right)$ continually until there was no further sulphite mist produced. The funnel was rinsed with a small volume of deionised water into the flask. The contents of the Erlenmeyer flask were cooled to room temperature, transferred with rinsing to a $25 \mathrm{~mL}$ volumetric flask and made up to $25 \mathrm{~mL}$ with deionised water. Samples were allowed to settle overnight, before the supernatant was isolated using a pipette.

Soil extracts were analysed using a Westco SmartChem 140 automated discrete analyser (Westco Scientific Instruments, Inc., Brookfield, CT, USA). This photometric based analysis utilised SmartChem 140 Method 420-3651 and was adapted for $P$ determination in soil extracts by replacing deionised water with $0.01 \mathrm{M} \mathrm{HNO}_{3}$ as the sample and reaction dilutant. However, the reaction chemistry remained unaltered with reaction of ammonium molybdate, antimony potassium tartate and dilute phosphorus solutions in an acid medium, forming an antimony-phospho-molybdate complex. This complex was reduced via the addition of ascorbic acid to form a blue complex. Measurement was made at a wavelength of $880 \mathrm{~nm}$ [43].

Blank digestions were prepared following the same procedure outlined above without sample soil additions. Final total P concentrations were offset by the $\mathrm{P}$ contributions of the blank solutions. Corrections were also made for soil moisture content, with five replicates of each soil sample heated at $105^{\circ} \mathrm{C}$ and cooled in desiccators until a constant mass was achieved.

All glassware used for total $\mathrm{P}$ determination was soaked in nitric acid $\left(2 \mathrm{M} \mathrm{HNO}_{3}\right)$ for a minimum of $7 \mathrm{~d}$ and rinsed three times with deionised water, soaked in deionised water and finally soaked in hydrochloric acid $(0.1 \mathrm{M} \mathrm{HCl})$ until used. Each soil sample was digested in duplicate and the concentration was averaged.

\subsubsection{Sodium Hydroxide-Ethylenediaminetetra-Acetic Acid (NaOH-EDTA) Soil Extraction}

The extraction of soil organic $\mathrm{P}$ using sodium hydroxide-ethylenediaminetetra-acetic acid (NaOH-EDTA) followed previously described standard procedures $[18,25]$.

A mixture of $2.5 \mathrm{~g}$ of soil sample and $50 \mathrm{~mL}$ of a solution containing $0.25 \mathrm{M} \mathrm{NaOH}$ and $0.05 \mathrm{M}$ $\mathrm{Na}_{2}$-EDTA was shaken end-on-end for $16 \mathrm{~h}$. Samples were centrifuged $(1300 \mathrm{~g})$, and the supernatant filtered through a Whatman (Maidestone, Kent, UK) \#42 filter paper. Samples were again analysed using a Westco SmartChem 140 automated, discrete analyser, as described for the total P extractions. The difference between total $\mathrm{P}$ and orthophosphate concentrations in the supernatant was used to estimate organic $P$. The remaining supernatant was frozen at $-60^{\circ} \mathrm{C}$ and freeze-dried.

\subsubsection{Solution ${ }^{31} \mathrm{P}$ NMR Analysis of $\mathrm{NaOH}-\mathrm{EDTA}$ Extracts}

Duplicate $500 \mathrm{mg}$ sub-samples of each freeze-dried $\mathrm{NaOH}$-EDTA extract were ground, re-dissolved in $5 \mathrm{~mL}$ of deionised water and centrifuged at $1400 \mathrm{~g}$ for $20 \mathrm{~min}$. The supernatant solution $(3.5 \mathrm{~mL})$ and $\mathrm{D}_{2} \mathrm{O}(0.3 \mathrm{~mL})$ were placed in a $10 \mathrm{~mm}$ NMR tube. The resultant $\mathrm{pH}$ was $>13$. Solution ${ }^{31} \mathrm{P}$ NMR spectra were acquired at $24{ }^{\circ} \mathrm{C}$ on a Varian INOVA400 NMR spectrometer (Varian, Palo Alta, CA, USA) at a ${ }^{31} \mathrm{P}$ frequency of $161.9 \mathrm{MHz}$. Recovery delays ranged from 4 to $18 \mathrm{~s}$ and were set to at least five times the $\mathrm{T}_{1}$ value of the orthophosphate resonance determined in preliminary inversion-recovery experiments (data not presented). Conditions used for ${ }^{31} \mathrm{P} N \mathrm{NMR}$ measurement include a $90^{\circ}$ pulse of 33 to $43 \mu \mathrm{s}$, an acquisition time of $1.0 \mathrm{~s}$ and broadband ${ }^{1} \mathrm{H}$ decoupling. Between 2112 and 12,624 scans were acquired for each sample, depending on the P concentration of the 
freeze-dried extract. Chemical shifts were referenced to $\beta$-glycerophosphate at $4.63 \mathrm{ppm}$ [44]. The spectra presented have a line broadening of $2 \mathrm{~Hz}$.

\section{Results}

The physical characteristics of the sampled sites and fertiliser application are summarised in Table 1. Evidently, the sampled sites in the Warragul area were much higher in elevation than those in the Maffra area. Also, the fertiliser applications for most of the sites in Warragul area were generally higher than those in the Maffra area.

Table 1. Information for individual sampling sites of the Warragul and Maffra areas.

\begin{tabular}{|c|c|c|c|c|c|c|c|c|}
\hline $\begin{array}{l}\text { Sampling } \\
\text { Sites }\end{array}$ & Measured Parameters & Site W1 & Site W2 & Site W3 & Site W4 & Site W5 & Site W6 & Site W7 \\
\hline \multirow{6}{*}{$\begin{array}{l}\text { Warragul } \\
\text { Area }\end{array}$} & $\begin{array}{l}\text { Estimated Slope } \\
\left(\mathrm{m} 100 \mathrm{~m}^{-1}\right)^{a}\end{array}$ & $<1.0$ & 2.9 & 11.7 & 9.2 & 11.7 & $<1.0$ & 4.0 \\
\hline & Elevation $(\mathrm{m})^{\mathrm{b}}$ & 134 & 133 & 159 & 150 & 134 & 108 & 112 \\
\hline & Soil Description $^{\mathrm{c}}$ & GCLD & GCLD & RCLF & RCLF & RCLF & GCLD & GSLD \\
\hline & $\begin{array}{l}\text { Period Post Fertiliser } \\
\text { Application }(\mathrm{d})\end{array}$ & 365 & 365 & 365 & 365 & $45^{*}$ & 20 & $730+$ \\
\hline & $\begin{array}{l}\text { Amount of Last Fert. } \\
\text { Application }\left(\mathrm{kg} \cdot \mathrm{P} \cdot \mathrm{ha}^{-1}\right)\end{array}$ & 24.8 & 24.8 & 24.8 & 24.8 & $3.7^{*}$ & 14.8 & $\mathrm{n} / \mathrm{a}$ \\
\hline & $\begin{array}{l}\text { Fert. Applied Over } 2 \text { Years } \\
\qquad\left(\mathrm{kg} \cdot \mathrm{P} \cdot \mathrm{ha}^{-1}\right)\end{array}$ & 24.8 & 24.8 & 24.8 & 24.8 & $3.7 *$ & 14.8 & $\mathrm{n} / \mathrm{a}$ \\
\hline $\begin{array}{l}\text { Sampling } \\
\text { Sites }\end{array}$ & Measured Parameters & Site M1 & Site M2 & Site M3 & Site M4 & Site M5 & Site M6 & Site M7 \\
\hline \multirow{6}{*}{$\begin{array}{l}\text { Maffra } \\
\text { Area }\end{array}$} & $\begin{array}{l}\text { Estimated Slope } \\
\left(\mathrm{m} 100 \mathrm{~m}^{-1}\right)^{a}\end{array}$ & $<1.0$ & $<1.0$ & 3.3 & $<1.0$ & $<1.0$ & $<1.0$ & $<1.0$ \\
\hline & Elevation $(\mathrm{m})^{b}$ & 46 & 43 & 36 & 33 & 28 & 33 & 33 \\
\hline & Soil Description $^{\mathrm{c}}$ & GRCLS & GRCLS & GRCLS & GRCLS & GYCLS & GCLS & GCLS \\
\hline & $\begin{array}{l}\text { Period Post Fertiliser } \\
\text { Application }(\mathrm{d})\end{array}$ & 365 & 45 & $1000+$ & $730+$ & 60 & 130 & 130 \\
\hline & $\begin{array}{c}\text { Amount of Last Fert. } \\
\text { Application }\left(\mathrm{kg} \cdot \mathrm{P} \cdot \mathrm{ha}^{-1}\right)\end{array}$ & 11.8 & 14.5 & $\mathrm{n} / \mathrm{a}$ & $\mathrm{n} / \mathrm{a}$ & 13.2 & 7.7 & 7.7 \\
\hline & $\begin{array}{l}\text { Fert. Applied Over } 2 \text { Years } \\
\left(\mathrm{kg} \cdot \mathrm{P} \cdot \mathrm{ha}^{-1}\right)\end{array}$ & 11.8 & 29.0 & $\mathrm{n} / \mathrm{a}$ & $\mathrm{n} / \mathrm{a}$ & 26.4 & 15.4 & 15.4 \\
\hline
\end{tabular}

${ }^{a}$ Estimated slope: Calculated as metres (m) fall over a $100 \mathrm{~m}$ area. Measured accounting for the sampling area; ${ }^{b}$ Elevation above sea level; ${ }^{c}$ Estimated soil description; GCLD = Grey clay loam Dermosol, RCLF = Red clay loam Ferrosol, GSLD = Grey sandy loam Dermosol, GRCLS = Grey/red clay loam Sodosol, GRCLS = Grey /yellow clay loam Sodosol, GCLS = Grey clay loam Sodosol; $*$ Site W5 has only received a single fertiliser application $\left(3.7 \mathrm{~kg} \cdot \mathrm{P} \cdot \mathrm{ha}^{-1}\right)$ in three years prior to sampling.

The results obtained for various soil properties for the selected sites are given in Table 2. Dual $\mathrm{pH}$ measurements were conducted on all soil samples, one using deionised water $\left(\mathrm{pH}_{\mathrm{W}}\right)$ and the other with calcium chloride $\left(\mathrm{pH}_{\mathrm{Ca}}\right)$ as extractants. Of these, the $\left(\mathrm{pH}_{\mathrm{Ca}}\right)$ test is more accurate, as it is more directly related to the $\mathrm{pH}$ a plant is exposed to in the soil. In general, $\left(\mathrm{pH}_{\mathrm{W}}\right)$ is usually about 0.5-0.9 higher than $\left(\mathrm{pH}_{\mathrm{Ca}}\right)$. The soil $\mathrm{pH}$ measurements of the samples obtained from the Warragul area were: $\mathrm{pH}_{\mathrm{W}} 5.0$ to 5.6 (average 5.3) and for $\mathrm{pH}_{\mathrm{Ca}} 4.1$ to 4.9 (average 4.6). These were only slightly higher for soil samples obtained from the Maffra area with $\mathrm{pH}_{\mathrm{W}} 4.9$ to 6.2 (average 5.7) and $\mathrm{pH}_{\mathrm{Ca}} 4.5$ to 5.6 (average 5.2).

The electrical conductivity, water extractable $\mathrm{P}$ and calcium chloride extractable P obtained for soil samples from the sites in the Maffra area were higher than those from the Warragul area. In contrast, the Colwell P obtained for sites in the Warragul area were higher than those from the Maffra area.

As evident in the results in Table 3, the total P concentrations ranged between 1779 and $3009 \mathrm{mg} \mathrm{P} \mathrm{kg}^{-1}$ for the classified soil from sites (W1-W6) in the Warragul area and ranged between 
1447 and $2381 \mathrm{mg} \mathrm{P} \mathrm{kg}^{-1}$ for the sites in Maffra area. This is somewhat reflective of the higher fertiliser application in the Warragul area. The total $\mathrm{P}$ concentrations obtained with the NaOH-EDTA extracts indicate that between $71.6 \%$ and $90.5 \%$ of the soil $\mathrm{P}$ was extracted. The proportion of $\mathrm{P}$ extracted with $\mathrm{NaOH}-\mathrm{EDTA}$ varied with soil type, and ranged from $85.9 \%$ to $90.5 \%$ for Dermosols (not including the unclassified site W7), $71.6 \%$ to $81.3 \%$ for Sodosols and $73.3 \%$ to $77.3 \%$ for Ferrosols. Organic P (the combination of monoester $\mathrm{P}$ and diester $\mathrm{P}$ ) represented between $21.3 \%$ and $50.2 \%$ (sites W3 and M4) of total extract $\mathrm{P}$ (Table 4). More specifically, the organic $\mathrm{P}$ in the Dermosols, Ferrosols and Sodosols ranged from $30.7 \%$ to $32.9 \%, 21.3 \%$ to $31.1 \%$ and $23.5 \%$ to $50.2 \%$, respectively. It is important to note that the extractable organic P obtained for Dermosols and Ferrosols were in reasonable agreement with the range of $20 \%$ to $30 \%$ obtained by Turner [45]. In contrast, the Sodosols gave much wider range of extractable organic $\mathrm{P}$ of $23.5 \%-50.2 \%$, but the recoveries obtained $(23.5 \%-31.6 \%)$ for soils collected from three of these sites (M1, M2 and M7) were also close to the range reported by Turner [46].

Table 2. Measured soil parameters for the surface soil $(0-20 \mathrm{~mm})$ of individual sampling sites of the Warragul and Maffra areas.

\begin{tabular}{|c|c|c|c|c|c|c|c|c|}
\hline $\begin{array}{l}\text { Sampling } \\
\text { Sites }\end{array}$ & Soil Parameters & Site W1 & Site W2 & Site W3 & Site W4 & Site W5 & Site W6 & Site W7 \\
\hline \multirow{8}{*}{$\begin{array}{l}\text { Warragul } \\
\text { Area }\end{array}$} & $\mathrm{pH}_{\mathrm{W}}$ & 5.5 & 5.4 & 5.0 & 5.1 & 5.4 & 5.6 & 5.2 \\
\hline & $\mathrm{pH}_{\mathrm{Ca}}$ & 4.9 & 4.8 & 4.4 & 4.3 & 4.8 & 4.8 & 4.1 \\
\hline & $\begin{array}{l}\text { Electrical Conductivity } \\
(\mathrm{dS} / \mathrm{m})\end{array}$ & 0.542 & 0.483 & 0.322 & 0.351 & 0.291 & 0.223 & 0.092 \\
\hline & Total P (mg P kg $\left.{ }^{-1}\right)$ & 1838 & 1941 & 3009 & 2680 & 1779 & 2062 & 1103 \\
\hline & Colwell P (mg P kg $\left.{ }^{-1}\right)$ & 730 & 671 & 418 & 446 & 126 & 251 & 110 \\
\hline & Olsen P (mg P kg $\left.{ }^{-1}\right)$ & 93 & 80 & 114 & 99 & 36 & 74 & 39 \\
\hline & $\begin{array}{l}\text { Water extractable } \mathrm{P} \\
\quad\left(\mathrm{mg} \mathrm{P} \mathrm{kg}^{-1}\right)\end{array}$ & 17.5 & 11.7 & 3.7 & 6.6 & 3.0 & 10.1 & 8.9 \\
\hline & $\begin{array}{c}\text { Calcium chloride } \\
\text { extractable P }\left(\mathrm{mg} \mathrm{P} \mathrm{kg}^{-1}\right)\end{array}$ & 6.7 & 4.3 & 1.7 & 2.9 & 0.9 & 5.0 & 3.3 \\
\hline $\begin{array}{l}\text { Sampling } \\
\text { Sites }\end{array}$ & Soil Parameters & Site M1 & Site M2 & Site M3 & Site M4 & Site M5 & Site M6 & Site M7 \\
\hline \multirow{8}{*}{$\begin{array}{l}\text { Maffra } \\
\text { Area }\end{array}$} & $\mathrm{pH}_{\mathrm{W}}$ & 5.3 & 5.6 & 4.9 & 6.1 & 5.4 & 6.0 & 6.2 \\
\hline & $\mathrm{pH}_{\mathrm{Ca}}$ & 4.9 & 5.3 & 4.5 & 5.3 & 5.0 & 5.6 & 5.6 \\
\hline & $\begin{array}{l}\text { Electrical Conductivity } \\
(\mathrm{dS} / \mathrm{m})\end{array}$ & 0.766 & 1.713 & 1.293 & 0.689 & 1.225 & 0.874 & 0.535 \\
\hline & Total P (mg P kg $\left.{ }^{-1}\right)$ & 1936 & 2381 & 1447 & 1470 & 1775 & 2000 & 1743 \\
\hline & Colwell P (mg P kg $\left.{ }^{-1}\right)$ & 314 & 443 & 106 & 89 & 334 & 319 & 306 \\
\hline & Olsen P (mg P kg $\left.{ }^{-1}\right)$ & 77 & 133 & 33 & 36 & 108 & 86 & 81 \\
\hline & $\begin{array}{l}\text { Water extractable } \mathrm{P} \\
\quad\left(\mathrm{mg} \mathrm{P} \mathrm{kg}^{-1}\right)\end{array}$ & 29.5 & 53.0 & 13.7 & 19.5 & 48.4 & 47.8 & 32.1 \\
\hline & $\begin{array}{c}\text { Calcium chloride } \\
\text { extractable } \mathrm{P}\left(\mathrm{mg} \mathrm{P} \mathrm{kg}^{-1}\right)\end{array}$ & 11.7 & 40.2 & 7.8 & 7.2 & 46.2 & 22.1 & 12.7 \\
\hline
\end{tabular}

Table 3. Selected soil and soil extract (NaOH-EDTA) characteristics of individual sampling sites of the Warragul and Maffra areas.

\begin{tabular}{|c|c|c|c|c|c|c|c|c|}
\hline $\begin{array}{c}\text { Sampling } \\
\text { Sites }\end{array}$ & Measured Parameters & Site W1 & Site W2 & Site W3 & Site W4 & Site W5 & Site W6 & Site W7 \\
\hline \multirow{5}{*}{$\begin{array}{c}\text { Warragul } \\
\text { Area }\end{array}$} & Soil Total P (mg P kg $\left.{ }^{-1}\right)$ & 1838 & 1941 & 3009 & 2680 & 1779 & 2062 & 1103 \\
\hline & Extract Total $\mathrm{P}\left(\mathrm{mg} \mathrm{P} \mathrm{kg}^{-1}\right)^{\mathrm{a}}$ & 1663 & 1708 & 2237 & 2072 & 1304 & 1771 & 836 \\
\hline & Extract Total $\mathrm{P}(\%)$ & 90.5 & 88.0 & 74.3 & 77.3 & 73.3 & 85.9 & 75.7 \\
\hline & Extract Organic $\mathrm{P}\left(\mathrm{mg} \mathrm{P} \mathrm{kg}^{-1}\right)$ & 577 & 559 & 508 & 547 & 447 & 572 & 399 \\
\hline & Extract Organic P $(\%)^{\mathrm{C}}$ & 34.7 & 32.7 & 22.7 & 26.4 & 34.3 & 32.3 & 47.8 \\
\hline
\end{tabular}


Table 3. Cont.

\begin{tabular}{|c|c|c|c|c|c|c|c|c|}
\hline $\begin{array}{l}\text { Sampling } \\
\text { Sites }\end{array}$ & Measured Parameters & Site M1 & Site M2 & Site M3 & Site M4 & Site M5 & Site M6 & Site M7 \\
\hline \multirow{5}{*}{$\begin{array}{c}\text { Maffra } \\
\text { Area }\end{array}$} & Soil Total P $\left(\mathrm{mg} \mathrm{P} \mathrm{kg}^{-1}\right)$ & 1936 & 2381 & 1447 & 1470 & 1775 & 2000 & 1743 \\
\hline & Extract Total $\mathrm{P}\left(\mathrm{mg} \mathrm{P} \mathrm{kg}^{-1}\right)^{\mathrm{a}}$ & 1472 & 1867 & 1174 & 1053 & 1378 & 1608 & 1417 \\
\hline & Extract Total $\mathrm{P}(\%)$ & 76.0 & 78.4 & 81.1 & 71.6 & 77.6 & 80.4 & 81.3 \\
\hline & Extract Organic $\mathrm{P}\left(\mathrm{mg} \mathrm{P} \mathrm{kg}^{-1}\right)$ & 494 & 666 & 628 & 591 & 692 & 678 & 364 \\
\hline & Extract Organic $\mathrm{P}(\%)^{\mathrm{c}}$ & 33.6 & 35.7 & 53.5 & 56.1 & 50.2 & 42.2 & 25.7 \\
\hline
\end{tabular}

a Total $\mathrm{P}$ method described in Materials and Methods section for $\mathrm{H}_{2} \mathrm{SO}_{4}$ digestion of $\mathrm{NaOH}$-EDTA extracts;

${ }^{b}$ Percentage of soil total $\mathrm{P}$ extracted using $\mathrm{NaOH}-\mathrm{EDTA} ;{ }^{\mathrm{c}}$ Organic $\mathrm{P}$ as a percentage of total $\mathrm{P}$ extracted using $\mathrm{NaOH}-\mathrm{EDTA}$.

The ${ }^{31} \mathrm{P}$ NMR spectra of $\mathrm{NaOH}-\mathrm{EDTA}$ extracts of all fourteen soils are shown in Figure 2 . These spectra are similar to ${ }^{31} \mathrm{P}$ NMR of NaOH-EDTA soil extracts published previously $[8,11,18,46,47]$. The distribution of $\mathrm{P}$ species, as determined by integration of the ${ }^{31} \mathrm{P}$ NMR spectra across broad chemical shift regions is given in Table 4.

Table 4. The percentage distribution of the total ${ }^{31}$ P NMR signal across four diagnostic chemical regions.

\begin{tabular}{|c|c|c|c|c|c|}
\hline $\begin{array}{l}\text { Sampling } \\
\text { Sites }\end{array}$ & Site & $\begin{array}{c}7 \text { to } 5.3 \mathrm{ppm} \\
\text { Orthophosphate (\%) }\end{array}$ & $\begin{array}{c}5.3 \text { to } 2 \text { ppm Monoester } \\
\text { Phosphate }(\%)\end{array}$ & $\begin{array}{c}0.5 \text { to }-1 \text { ppm Diester } \\
\text { Phosphate }(\%)\end{array}$ & $\begin{array}{c}-4.5 \text { to }-5.5 \mathrm{ppm} \\
\text { Pyrophosphate }(\%)\end{array}$ \\
\hline \multirow{7}{*}{$\begin{array}{c}\text { Warragul } \\
\text { Area }\end{array}$} & W1 & $65.3(0.6)$ & $31.0(0.1)$ & $1.9(0.1)$ & $1.8(0.4)$ \\
\hline & W2 & $67.3(0.1)$ & $30.1(0.5)$ & $1.5(0.2)$ & $1.1(0.4)$ \\
\hline & W3 & 77.3 (1.6) & $19.8(1.5)$ & $1.5(0.3)$ & $1.4(0.2)$ \\
\hline & W4 & $73.6(0.0)$ & $23.4(0.1)$ & $1.5(0.1)$ & $1.6(0.0)$ \\
\hline & W5 & $65.7(1.2)$ & $28.6(0.8)$ & $2.5(0.2)$ & $3.1(0.2)$ \\
\hline & W6 & $67.7(0.1)$ & $28.9(0.4)$ & $1.8(0.1)$ & $1.6(0.4)$ \\
\hline & W7 & $52.2(2.2)$ & $39.6(0.4)$ & $5.7(0.9)$ & $2.6(0.9)$ \\
\hline \multirow{7}{*}{$\begin{array}{c}\text { Maffra } \\
\text { Area }\end{array}$} & M1 & $66.4(1.4)$ & $28.2(0.6)$ & $2.0(0.6)$ & $3.3(0.2)$ \\
\hline & M2 & $64.3(0.3)$ & $29.1(0.1)$ & $2.5(0.0)$ & $4.1(0.2)$ \\
\hline & M3 & $46.5(1.0)$ & $44.6(0.3)$ & $3.8(1.1)$ & $5.0(0.2)$ \\
\hline & M4 & $43.9(2.1)$ & $46.4(0.6)$ & $3.8(1.7)$ & $5.9(1.0)$ \\
\hline & M5 & $49.8(0.3)$ & $37.9(0.0)$ & $3.8(0.2)$ & $8.5(0.1)$ \\
\hline & M6 & 57.8 (3.7) & $33.0(1.9)$ & $3.9(1.3)$ & $5.2(0.5)$ \\
\hline & M7 & $74.3(2.1)$ & $22.2(2.1)$ & $1.3(0.8)$ & $2.2(0.8)$ \\
\hline \multicolumn{2}{|c|}{ Average } & 62.3 & 31.6 & 2.7 & 3.4 \\
\hline
\end{tabular}

Standard deviations for duplicate NMR analysis shown in brackets.

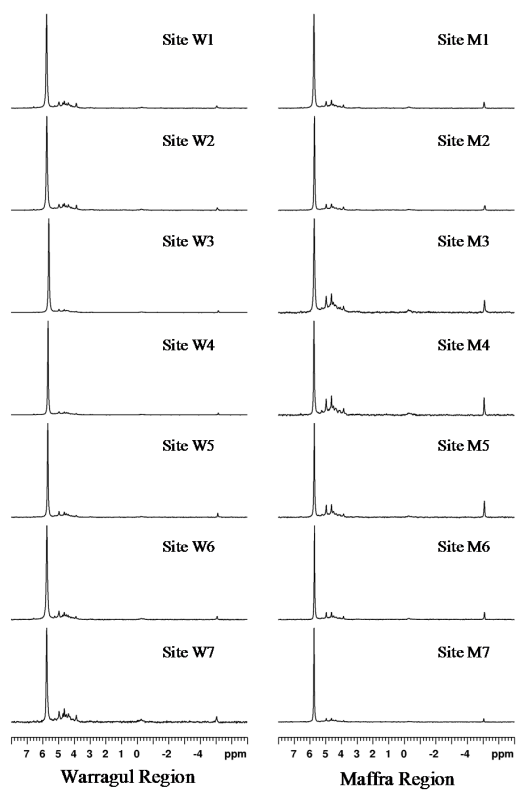

Figure 2. Solution ${ }^{31} \mathrm{P}$ NMR spectra of $\mathrm{NaOH}-E D T A$ soil extracts. 
As in previous studies, the most abundant $P$ species in most of the soils was orthophosphate [18]. With a chemical shift from 7.0 to $5.3 \mathrm{ppm}$ in the NMR spectra, orthophosphate accounts for between $43.9 \%$ and $77.3 \%$ of the total signal intensity in these soils. An exception was site M4, which contained marginally more (46.4\%) monoester P than orthophosphate P (43.9\%). Across all soils, monoester phosphate (between 5.3 and $2.0 \mathrm{ppm}$ ) represented $19.8 \%$ to $46.4 \%$ of the total $\mathrm{P}$ (average $31.6 \%$ ).

Diester phosphate (between 0.5 and $-1.0 \mathrm{ppm}$ ) on average contributed $2.7 \%$ of signal intensity, whereas pyrophosphate (between -4.5 and $-5.5 \mathrm{ppm}$ ) averaged $3.4 \%$. Diester phosphate appeared to account for a lower proportion of the signal intensity for the Warragul samples (averaging $2.3 \%$ ) than those from the Maffra area (3.0\%). This difference becomes more apparent when the contribution of W7 is removed from these calculations, lowering the average diester phosphate contribution for the Warragul area to $1.8 \%$.

Site W7 contained the most diester phosphate (5.7\%) of all the soils tested. This site was different to others due to its unique soil type, a grey sandy loam. Based on other soils surrounding its location, soil from site W7 featured Dermosol characteristics.

Figure 3 shows the scatter plots obtained between the concentrations of the various inorganic and organic phosphates found in all soil samples. It is obvious that, given the limited number of sampling sites considered in this initial study, it is difficult to identify clear correlation between many of these P species. Notwithstanding this limitation, correlation between the concentrations of some of these species is still clearly evident and these will be highlighted later in the discussion section.

(a)

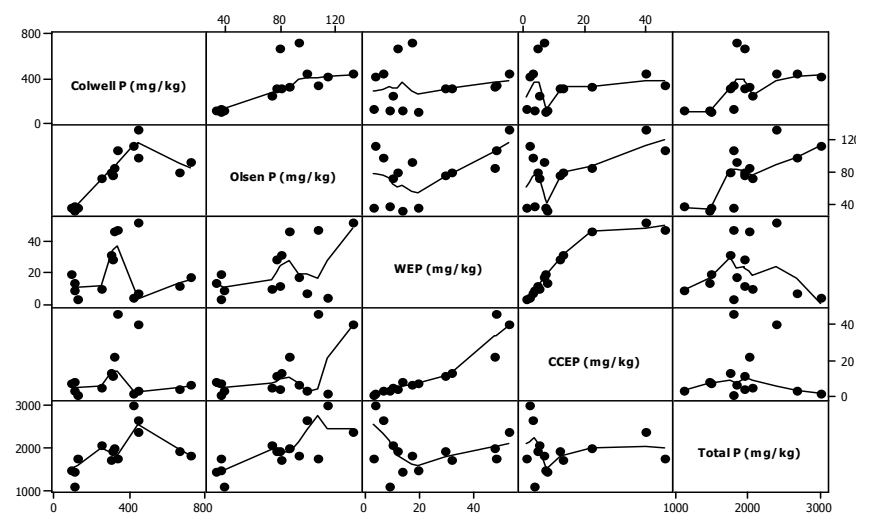

WEP - Water extractable P, CCEP - Calcium chloride extractable P

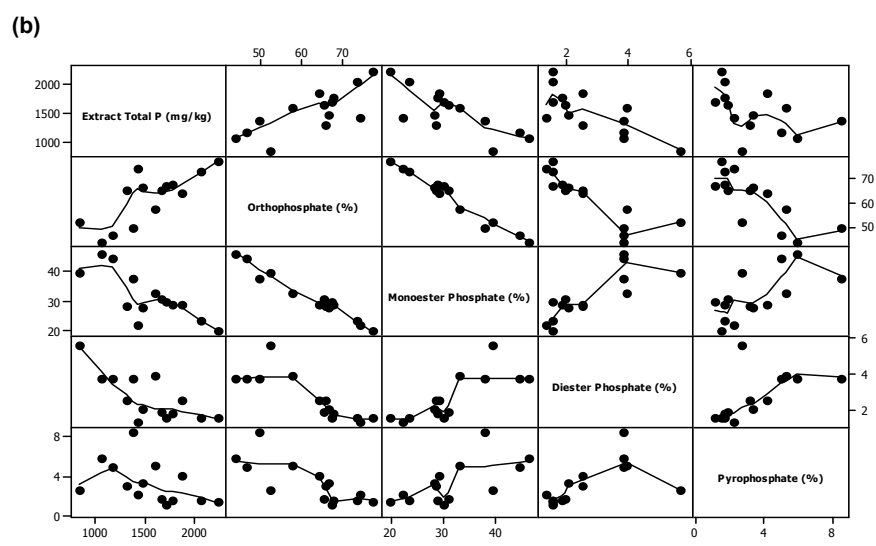

Figure 3. Scatter plots of the trend between some of the inorganic and organic P levels in the soil samples. (a) Colwell P, Olsen P, water extractable P (WEP), calcium chloride extractable P (CCEP) and Total $\mathrm{P}$ as $\mathrm{mg} / \mathrm{kg}$; (b) Extractable total $\mathrm{P}$, orthophosphate, monoester $\mathrm{P}$, diester $\mathrm{P}$ and pyrophosphate as percentage (\%). 


\section{Discussion}

By removing fertiliser variables, such as timing and rate, some clear differences can be seen between soil types. These differences are most clearly demonstrated when comparing sites W1 and W2 (grey clay loam Dermosols) to sites W3 and W4 (red clay loam Ferrosols). Although separate, each of these sites were managed as a single site utilising similar farm management practices, with each receiving identical recent $\mathrm{P}$ fertiliser additions $\left(24.8 \mathrm{~kg} \cdot \mathrm{P} \cdot \mathrm{ha}^{-1}, 365 \mathrm{~d}\right)$. Although separated by less than $2 \mathrm{~km}$, these pairs of sites showed some clear differences that were attributed predominantly to soil type and this will be discussed in more detail later in this section. Total soil P concentrations were much lower for sites W1 and W2 (1838 and $1941 \mathrm{mg} \mathrm{P} \mathrm{kg}^{-1}$ ) than sites W3 and W4 (3009 and $2680 \mathrm{mg} \mathrm{P} \mathrm{kg}^{-1}$ ). Based on site averages, these higher total P concentrations, which were $51 \%$ greater for the Ferrosol sites, were not reflected in the results for the agronomic soil testing, with the Dermosol sites (W1 and W2) giving higher Colwell P values than the Ferrosol sites (W3 and W4), and similar Olsen P values (Table 2).

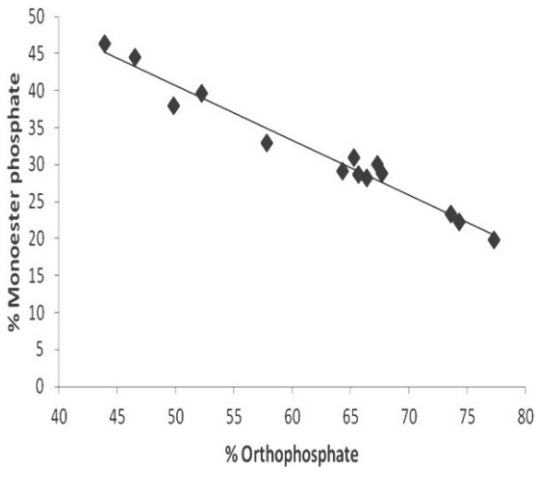

(a)

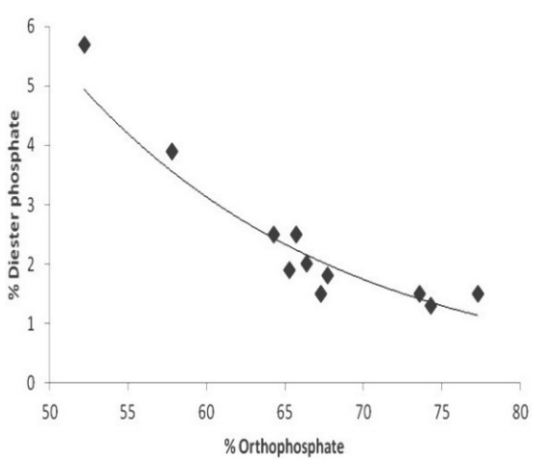

(c)

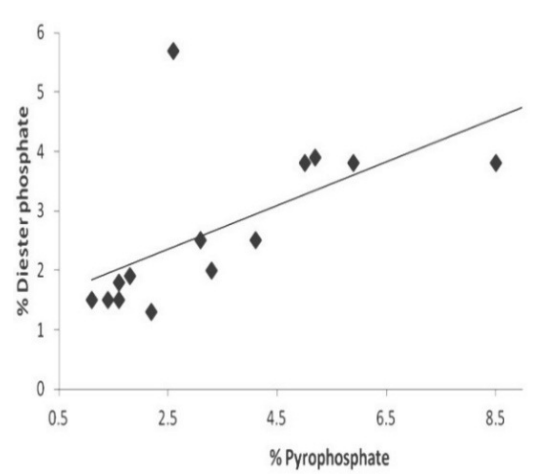

(b)

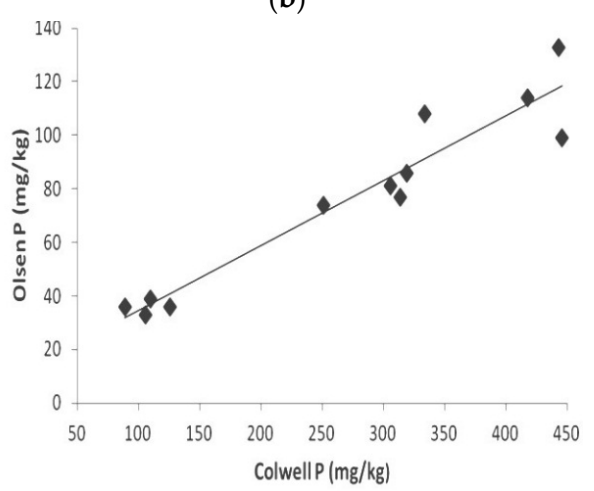

(d)

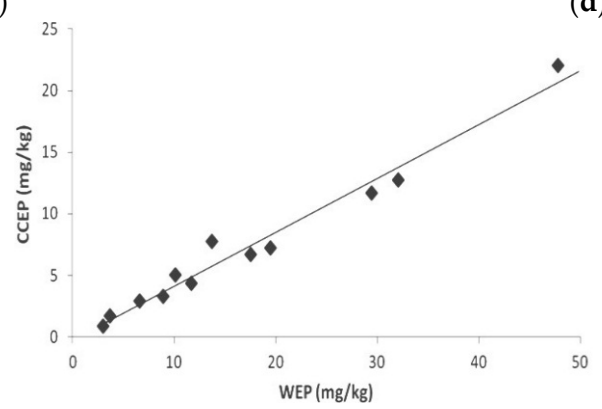

(e)

Figure 4. Selected scatter plots demonstrating correlation between: (a) monoester $\mathrm{P}$ and orthophosphate; (b) diester P and pyrophosphate; (c) diester P andorthophosphate; (d) Olsen P and Colwell P; (e) CCEP and WEP. 
Despite slight management disparity, there were discrepancies when comparing the P composition within the soils from Maffra sites M2 and M5 using NMR analysis. The red Sodosol (M2) gave 64.3\% of total $\mathrm{P}$ in the form of orthophosphate (inorganic), whereas it was $49.8 \%$ for the yellow Sodosol (M5). Another feature of the yellow Sodosol is the relatively high proportion of pyrophosphate (8.5\%) compared to all other soils. This was $44 \%$ higher than the next highest pyrophosphate percentage (site M4, 5.9\%) and more than doubled the highest proportion achieved in soils from the Warragul area (ranging between $1.1 \%$ and $3.1 \%$ ). As with any alkaline organic $P$ extraction procedure there is always the possibility that hydrolysis may have influenced these results. Pyrophosphate is unstable in aqueous solution and some may have been hydrolysed during the extraction into inorganic phosphate $[23,48]$. To some degree, the concentration of monoester phosphate is likely to be overestimated through the degradation of diester phosphate during the extraction process $[48,49]$. This possibility needs to be taken in consideration when viewing these results.

The lowest soil orthophosphate levels also corresponded with the lowest fertiliser inputs for the Maffra soils (site M3, 46.5\% and site M4 43.9\%). Sites M3 and M4, which are of a similar soil type, had not received P-based fertilisers for at least two years prior to soil sampling. Not surprisingly, these soils had the lowest total P concentrations (1447 mg P kg $\mathrm{m}^{-1}$ and $1470 \mathrm{mg} \mathrm{P} \mathrm{kg}^{-1}$ for M3 and M4, respectively), with the exception of site W7. Again these low fertiliser rates resulted in a high proportion of monoester $\mathrm{P}$ (44.6\% and $46.4 \%$ for M3 and M4, respectively). This view is well supported by the scatter plot of monoester P and orthophosphate levels shown in Figure 4a. It is clearly obvious that monoester P level was highest when orthophosphate level in the soil was lowest.

To better understand the cause of these variations and differences, it was necessary to further discuss the influence of important parameters, such as soil type and management practices, including fertilisation, moisture, $\mathrm{pH}$ and slope/elevation variations.

\subsection{Influence of Soil Type}

The use of NMR spectroscopy for investigating the P complexes of each soil type revealed distinct differences in signal strength distribution. Typically, diester phosphate and pyrophosphate were similar irrespective of soil type, but those of monoester phosphate and orthophosphate were different. This view is well supported by the scatter plot between diester $\mathrm{P}$ and pyrophosphate concentrations. Figure $4 \mathrm{~b}$ shows that, with the exception of two outliers, reasonably good correlation was found between the concentrations of these two P species. Also, the scatter plot in Figure $4 \mathrm{c}$ reveals that diester $\mathrm{P}$ level is highest where fertilise input is lowest, as reflected by low orthophosphate level. This indicates that during low fertilizer input, a relatively large proportion of $\mathrm{P}$ is stored in soil in the organic diester $\mathrm{P}$ form.

The average proportion of orthophosphate was $66.8 \%$ for the grey Dermosol (sites W1, W2, W6) and $72.2 \%$ for the red Ferrosol sites (sites W3, W4, W5). The monoester phosphate region on average accounted for $30.0 \%$ and $23.9 \%$ of signal intensity for Dermosol and Ferrosol soils, respectively.

With the longer exposure (16 h) of the extracted $\mathrm{P}$ from the soil to the NaOH-EDTA solution, it is possible that the hydrolysis of labile $\mathrm{P}$ forms can lead to production of artefacts which can influence the observed difference of the $\mathrm{P}$ forms to some extent. However, the differences in soil mineralogy which reflects soil formation processes will have stronger influence on the observed trends of the $P$ forms. For example, by definition, Ferrosols have B2 horizons which are high in iron (Fe) content [39]. This may also be reflected in the surface soil horizon (A) as Ferrosols lack strong texture contrast between the A and B horizons [39]. Soils high in Fe sorb P strongly due to their variable charged oxides and, therefore, Fe is an important factor in soil P sorption [50,51]. Hence, the presence of higher Fe concentrations may account, in part, for the higher orthophosphate proportion (Table 4), much higher total P concentrations (Table 2), and relatively low concentrations of other soil P measurements (Table 2) in the Ferrosol sites with the same fertiliser application rates (that is, Dermosol sites W1 and W2 compared to Ferrosol sites W3 and W4). 
The Ferrosol sites (W3 and W4) had average concentrations of $432 \mathrm{mg} \mathrm{P} \mathrm{kg}^{-1}$ and $107 \mathrm{mg} \mathrm{P} \mathrm{kg}^{-1}$ for Colwell P and Olsen P, respectively. The comparative concentrations for the Dermosol sites (W1 and W2) were $701 \mathrm{mg} \mathrm{P} \mathrm{kg}^{-1}$ for Colwell $\mathrm{P}$ and $87 \mathrm{mg} \mathrm{P} \mathrm{kg}^{-1}$ for Olsen P. The higher Olsen P concentrations in soil from the Ferrosol sites indicate that the soil had more plant available P (as indicated by Olsen $P$ values) than those from the Dermosol sites. On the other hand, the much higher Colwell P value obtained for the Dermosol sites indicate that the soil contains more structurally bound phosphate reserve than soil from the Ferrosol sites. Furthermore, the lower Colwell P obtained for soil from all of the Ferrosol sites (including site W5) is consistent with the lower total P extracted ( $73.3 \%-77.3 \%)$ with the NaOH-EDTA solution (Table 3) compared with those of the Dermosol sites, including site W6 (85.9\%-90.5\%). The significant difference also supports the view that the Dermosols have higher structurally bound (reserve) P. In general, the higher Colwell $\mathrm{P}$ obtained for sites in the Warragul area (110-730 $\mathrm{mg} \mathrm{P} \mathrm{kg}^{-1}$ ) than those in Maffra area (89-443 $\mathrm{mg} \mathrm{P} \mathrm{kg}^{-1}$ ) indicates higher structurally bound (reserve) $\mathrm{P}$ in soil within the Warragul area.

In spite of the differences in the Olsen $P$ and Colwell P levels in the different soil samples, Figure $4 \mathrm{~d}$ shows that there is a reasonably good correlation between the Olsen P and Colwell P levels obtained for other soil samples when the W1 and W2 Dermosol sites are removed. This observation supports the view that either of these parameters can be used to gain a reasonable indication of plant available $\mathrm{P}$.

The differences between the soil from Dermosol (sites W1 and W2) and Ferrosol sites (sites W3 and W4) with the same fertiliser treatments were also evident in the environmental soil tests. The environmental soil test utilised weak extractants (namely deionised water and $0.1 \mathrm{M}$ calcium chloride) to provide insight into $P$ that may be environmentally available. As reflected by the results in Table 2, the use of these weak extractants (water and calcium chloride) for the environmental soil tests gave comparable lower $\mathrm{P}$ concentrations than Olsen $\mathrm{P}$ and Colwell $\mathrm{P}$ values. The average water extractable $\mathrm{P}$ (WEP) and calcium chloride extractable P (CCEP) concentrations for the Dermosol sites were $14.6 \mathrm{mg} \mathrm{P} \mathrm{kg}^{-1}$ and $5.5 \mathrm{mg} \mathrm{P} \mathrm{kg}^{-1}$, respectively. In contrast, the WEP and CCEP concentrations for the Ferrosol sites were considerably lower, averaging 5.1 and $2.3 \mathrm{mg} \mathrm{P} \mathrm{kg}^{-1}$, respectively, corresponding to $35 \%$ of WEP and $42 \%$ of CCEP concentrations found for the Dermosol samples. Interestingly, these results indicate that while on average the Ferrosol sites have similar plant available P (higher Olsen $P$ value) to those of the Dermosol sites, the reverse was revealed by the environmental soil test results. These observations indicate a possible distinction between plant available P and environmentally available P. The higher environmentally available P concentrations observed for the Dermosol sites are reflective of their higher Colwell $P$ values.

More interestingly, the WEP and CCEP concentrations obtained for the sites in the Maffra area (13.7-53.0 mg P kg${ }^{-1}$ and 7.2-46.2 $\mathrm{mg} \mathrm{P} \mathrm{kg}^{-1}$, respectively) were much higher than those from Warragul areas (3.0-17.5 $\mathrm{mg} \mathrm{P} \mathrm{kg}^{-1}$ and $0.9-6.7 \mathrm{mg} \mathrm{P} \mathrm{kg}^{-1}$, respectively). This observation indicates that environmental leaching of $\mathrm{P}$ occurs more readily from the Sodosols than from the Dermosols and Ferrosols.

The results for sampling sites in the Maffra area also suggest differences due to soil characteristics. Even though all soils from the sites in Maffra area were Sodosols, there were still some variations in soil type, predominantly reflecting differences in subsurface soil colour (Table 1).

Notwithstanding the variation in the environmental P levels with soil type, Figure 4e shows that there is a very good correlation between CCEP and WEP levels. This observation suggests that either of these parameters may be reasonably used to gain an indication of the environmental P level in soil.

\subsection{Influence of Management Practices}

\subsubsection{Fertiliser Variations}

The impact of different management practices applied to the sampling sites were also investigated. An important feature of site W7 is that it had not received any fertiliser P applications for a minimum 
of two years prior to sampling. Thus, a combination of soil type (the only grey sandy loam Dermosol) and fertiliser application is likely to be the cause of the difference between site W7 and the other sites.

The lack of fertiliser inputs to site W7 is clearly reflected in the total $\mathrm{P}\left(1103 \mathrm{mg} \mathrm{P} \mathrm{kg}^{-1}\right)$, extracted total P (836 mg P kg${ }^{-1}$ ) and orthophosphate portion (52.2\%) measurements, each the lowest among the Warragul sites. The lower orthophosphate in this soil, in turn, increased the relative proportions of other soil P types, with W7 having the highest proportion of monoester P $(39.6 \%)$ and the second highest proportion of pyrophosphate $(2.6 \%)$ (Table 4$)$. This view is well supported by the scatter plots in Figure 4.

The apparent increase in orthophosphate concentrations due to fertiliser application is not unexpected. In fact the purpose of any type of fertiliser $\mathrm{P}$ application is to increase available $\mathrm{P}$ for pasture production and all fertiliser $\mathrm{P}$ inputs for the sampled site were inorganic blends. Depending on soil texture, fertilisers additions have also been found to increase soil organic $\mathrm{P}$, especially monoester P $[23,52]$.

Sites M1 to M4 also had similar soil characteristics, but received different fertiliser P inputs over different periods. Site M1 had $11.8 \mathrm{~kg} \cdot \mathrm{P} \cdot \mathrm{ha}^{-1}$ applied approximately $365 \mathrm{~d}$ prior to sampling, whereas $14.5 \mathrm{~kg} \cdot \mathrm{P} \cdot \mathrm{ha}^{-1}$ was applied approximately $45 \mathrm{~d}$ pre-sampling to site M2 (Table 1). Site M2 also had an extra $14.5 \mathrm{~kg} \cdot \mathrm{P} \cdot \mathrm{ha}^{-1}$ addition around $400 \mathrm{~d}$ before sampling. The extra and more recent fertiliser additions appears to be reflected in the soil $\mathrm{P}$ concentrations (total $\mathrm{P}$ and orthophosphate portion). All measured P concentrations were higher at site M2 than at site M1, including total P ( $23 \%$ higher), Colwell P (41\%), Olsen P (73\%), WEP (80\%) and CCEP (24\%). The CCEP concentrations appears to be most affected by the recent fertiliser additions. Although the fertiliser additions are not enough to fully account for differences between P capacity measurements (namely total P and Colwell P), they may also be indicative of different long term management strategies between the sites. Interestingly, these differences were also reflected by three of the different proportions in the four ${ }^{31} \mathrm{P}$ NMR chemical regions. Corresponding signal proportions for sites M1 and M2 were orthophosphate $(66.4 \%$ and $64.3 \%)$, monoester P (28.2\% and $29.1 \%)$, diester P $(2.0 \%$ and $2.5 \%)$ and pyrophosphate $(3.3 \%$ and $4.1 \%)$. Only the orthophosphate proportion of the soil from site M2 was lower than that obtained from site M1. Although the difference is small (2.1\%) and could be insignificant, it may also indicate that soil from site M2 contained higher proportion of structurally bound (reserve) P, as reflected by its higher Colwell P value (Table 2).

The results reported for the Ferrosol site W5 must also be viewed carefully. Although this site received a fertiliser addition close $(45 \mathrm{~d})$ to the time of sampling the total $\mathrm{P}$ input was relatively minor, equivalent to $3.7 \mathrm{~kg} \cdot \mathrm{P} \cdot \mathrm{ha}^{-1}$. This application was the only fertiliser $\mathrm{P}$ application for at least a three year period prior to sampling. The apparent lack of fertiliser input was obvious with all soil $\mathrm{P}$ measurements lower at site W5 compared with soil from other Ferrosol sites (W3 and W4).

The difference is particularly noticeable when comparing the agronomic soil $\mathrm{P}$ test results of the Colwell and Olsen P values. The average concentrations (sites W3 and W4) of $432 \mathrm{mg} \mathrm{P} \mathrm{kg}^{-1}$ (Colwell P) and $107 \mathrm{mg} \mathrm{P} \mathrm{kg}^{-1}$ (Olsen P) were clearly higher than those found for site W5 (Colwell P $126 \mathrm{mg} \mathrm{P} \mathrm{kg}^{-1}$ and Olsen P $36 \mathrm{mg} \mathrm{P} \mathrm{kg}^{-1}$ ). Site W5 also had the lowest WEP and CCEP concentrations of all sampled sites. Fertiliser application differences are also notable when interpreting the NMR spectra for this site. Even with the recent inorganic fertiliser addition prior to sampling, the proportion of orthophosphate averaged $9.8 \%$ less than other Ferrosol sites. However, this site had the highest proportion of pyrophosphate at $3.1 \%$ of all the sites in the Warragul area. Thus, indicating that the retention of $\mathrm{P}$ as pyrophosphate and other insoluble inorganic/organic $\mathrm{P}$ may account for the low WEP and CCEP concentrations obtained for this soil sample.

As with the Warragul sites fertiliser management variations were also evident for the Maffra sites. Site $\mathrm{M} 2$ received a $\mathrm{P}$ fertiliser application $15 \mathrm{~d}$ closer to sampling in comparison with M5 (45 d compared to $60 \mathrm{~d}$ ). Slightly higher $\mathrm{P}$ fertiliser application rates (possibly over an extended period) at site M2 may be reflected in the measured soil P concentrations, particularly total P concentrations (2381 $\mathrm{mg} \mathrm{P} \mathrm{kg}^{-1}$ for site M2 and $1775 \mathrm{mg} \mathrm{P} \mathrm{kg}^{-1}$ for site M5). Despite fertiliser additions (13.2 kg. P. ha ${ }^{-1}, 60 \mathrm{~d}$ ), 
site M5 was one of three (also sites M3 and M4) sample locations which had a lower proportion of orthophosphate than the combination of monoester $\mathrm{P}$, diester $\mathrm{P}$ and pyrophosphate. The low proportion of orthophosphate at site M5 is an interesting observation due to the relatively recent fertiliser application to the site $(60 \mathrm{~d})$. In fact, this results is more reflective of other Maffra soil types which had not received $\mathrm{P}$ fertiliser input for an extended period $(>730 \mathrm{~d})$. The low proportion of orthophosphate may also be due to insufficient elapsed time to allow fertiliser $\mathrm{P}$ to be solubilised and incorporated into the soil structure. The NMR results for site M5 also do not reflect what was found for WEP (48.4 $\mathrm{mg} \mathrm{P} \mathrm{kg}^{-1}$ ) and CCEP $\left(46.2 \mathrm{mg} \mathrm{P} \mathrm{kg}^{-1}\right)$ analysis. This was the highest CCEP concentration and second highest WEP concentration measured across all sites. The CCEP and WEP measurements are often associated with "available" P measurement and this would be expected to indicate an increased presence of inorganic orthophosphate. These results appeared to be more reflective of the recent fertiliser additions for the Maffra area as site M2 (WEP $53.0 \mathrm{mg} \mathrm{P} \mathrm{kg}^{-1}$ and CCEP $40.2 \mathrm{mg} \mathrm{P} \mathrm{kg}^{-1}$ ) produced similar results for recent fertiliser addition.

An interesting comparison can be made between sites M6 and M7. Both of these sites are located on the Macalister Research Farm, a dairy farm situated in the MID of south-east Victoria. Each of the irrigation bays measured were a vertic, mesonatric grey Sodosol [39]. Site M6 (graded) was laser graded six years prior to sampling which involved disk ploughing followed by minor cutting and filling. The top soil was retained within the irrigation bay. Site M7 (established) had not been significantly altered through cultivation ( $>20$ years prior). Each of these sites received identical $P$ fertiliser application (15.4 kg. P. ha ${ }^{-1}$ ) and timing (130 d) for the two years preceding soil sampling.

Even after a six year period from the laser grading, there still appears to be a significant difference between the graded and established sites. This was reflected in both soil P measurements and organic $\mathrm{P}$ composition. All soil $\mathrm{P}$ concentrations for the $20 \mathrm{~mm}$ depth were higher in the established bay (site M6), particularly the environmental P tests (total P 15\% greater; Colwell P 4\%; Olsen P 6\%; WEP $49 \%$; CCEP 74\%). This was not completely unexpected. Surface soil and accumulated P is redistributed throughout the soil profile due to laser-grading process. A possible explanation for $\mathrm{P}$ being held in a more available form is that the mixing of the soil profile may, in turn, expose fresh $\mathrm{P}$ adsorption sites within the soil. With more adsorption sites exposed, graded bays could have a greater capacity to convert newly adsorbed $\mathrm{P}$ from the available form to occluded $\mathrm{P}$ over time. The processes of converting available $\mathrm{P}$ to occluded $\mathrm{P}$ may diminish with time with $\mathrm{P}$ binding within the soil structure being utilised. Hence, established bays may have a reduced ability to bind P into its soil structure, holding $\mathrm{P}$ in a more "available" form.

The ${ }^{31} \mathrm{P}$ NMR phosphate distribution of the graded site (site M6) and established irrigation bay (site M7) in Table 4 shows comparatively high orthophosphate concentrations/proportions for site M7. This appear most closely linked to the higher concentrations of the environmental soil P tests (namely WEP and CCEP) for the established bay site. Whether this relationship exists or it is coincidental requires more in-depth study. Regardless these differences are again likely due to the redistribution, in this case organic material and organic $P$ that has accumulated in the surface soil throughout the soil profile. Whether the redistribution of $\mathrm{P}$ and different forms also occurs at different cultivation and soil depths is beyond the scope of this study and requires further investigation.

A previous study [49] has shown that soil left bare fallow for a 20 year period after ploughing had less organic P compared with a grassland reference soil. The study indicated that proportion of organic monoester P remained the same while proportion of diester P decreased over time. Diester P loss did not appear to have occurred in our study with similar monoester and diester $\mathrm{P}$ ratios maintained whether the sites had been laser graded (M6) or was established (M7) (Table 4). The results seem to support the previously mentioned dilution effect of organic $\mathrm{P}$ through the soil profile.

\subsubsection{Moisture Variations}

Moisture is a factor which may impact on soil P speciation and organic P composition. Moisture has been shown to increase organic P forms in soil [23]. For example, an increase in diester P and, 
indeed, other organic $\mathrm{P}$ components have been linked to increased moisture and acidic $\mathrm{pH}$ [23]. This may be due to lower decomposition rates and/or decreased microbial biomass. However, another study has shown a positive correlation with increased microbial populations for pasture based soils $[23,48]$. Hence, the influences of microbial populations are still debatable due to variable results related to the heterogeneity of diester $\mathrm{P}[23,53]$.

Investigation of moisture inputs received by sampled sites showed a stark difference between the rainfall averages of the Maffra $(582 \mathrm{~mm})$ and the Warragul areas $(1021 \mathrm{~mm})$. Even though the Maffra area received only $57 \%$ of the average rainfall of Warragul, this is somewhat offset if not surpassed, due to all sites in the Maffra area receiving boarder-check (flood) irrigation as part of the MID. The timing of the irrigation applications may also be important as the irrigation season of the MID occurs annually between 15 August and 15 May, encompassing the Australian summer. Sampling for the Maffra area occurred during April 2007 and was towards the end of the regular irrigation season. Without intensive monitoring of moisture inputs at each individual site it is difficult to estimate the impact of soil hydration on the final results. This intensive and costly monitoring is outside the scope of the present study. Even so, there may be some correlation between the irrigated system (Maffra), with a relatively constant water supply, and the rain-fed system (Warragul). As moisture is known to increase soil organic P [23] this may account for the much higher organic $\mathrm{P}$ (combined monester $\mathrm{P}$ and diester $\mathrm{P}$ ) proportions found in sites in the Maffra area, averaging $37.5 \%$ compared with those in the Warragul area which averaged $31.1 \%$.

Soil moisture may have also been a factor affecting sites within a sampled area. The Dermosols of sites W1 and W2 are located on a flood plain area and, as such, would be subjected to saturation and flooding during different seasonal events. However, this possibility was not deemed sufficient to class the soil as a hydrosol for the purpose of this study. Nevertheless, moisture may be considered an important factor for the organic P composition of soil from sites W1 and W2. In wetland soils, organic P has been shown to be predominant $[54,55]$. This may also account for the large difference in organic $P$ concentration (combined monoester P and diester P) obtained for soil from Dermosol sites W1 and W2 (32.9\% and 31.6\%) compared to those from Ferrosol sites W3 and W4 (21.3\% and 24.9\%) under the same farm management. However, it is important to note that prior to sampling, both Warragul and Maffra areas were subjected to extended drought conditions ( $>3$ years). For the period between 2002 and 2006 inclusive, the Warragul and Maffra areas received approximately 79\% (ranging between $68 \%$ and $93 \%$ ) and $78 \%$ (ranging between $61 \%$ and $90 \%$ ) of the long term (>100 years) average rainfall respectively [56]. Hence, it is unlikely that the Dermosol sites W1 and W2 were subject to normal soil flooding and saturation processes throughout the extended dry period. Nevertheless, the generally higher moisture content at these sites over an extended period may be sufficient to enable formation of higher organic P concentration than in the Ferrosol sites.

\subsubsection{Soil $\mathrm{pH}$}

Soil $\mathrm{pH}$ is a very important consideration when evaluating the speciation of $\mathrm{P}$ in soil. This is due to the influence of $\mathrm{pH}$ on various factors including extractability of different $\mathrm{P}$ forms, microbial populations and organic material breakdown [1,23]. For example, in one study, acidic to neutral $\mathrm{pH}$ ranges of Spanish forest soil showed a negative correlation with monoester P concentrations [57,58]. Regardless of the extracting medium, $\mathrm{pH}$ does not appear to be drastically different between sites and sampled areas, as all soils measured were slightly acidic in nature, as indicated by the results given in Table 2. For this reason, it was expected that the effect of these $\mathrm{pH}$ differences between sites would be minimal.

\subsubsection{Slope and Elevation}

The slope and elevation of the measured sampling sites were recorded to determine possible impact on the results obtained. In particular, it is known that the slope of a sampling site may impact on excess overland flow (surface water runoff) [59] and can, in turn, influence P retention and/or 
transport. In south-eastern Australia and other temperate regions, surface runoff is considered the predominant pathway for $P$ transport [60-62].

Overall, the site slope and elevation appeared to have nominal impacts on the soil P concentrations and $\mathrm{P}$ speciation of the measured sites. However, if these observations are also reflected in $\mathrm{P}$ transport in surface runoff, further investigation would be needed. If slope and elevation differences exist, these appeared to be overshadowed by other variables, particularly area sampled, soil type, fertiliser input and timing. In fact, the differences between the area sampled, slope and elevation are inherently linked in this case. This is due to the Warragul area being found in rolling hills and the Maffra area of generally flat irrigation bays and topography. Hence, both average elevation and slope are clearly

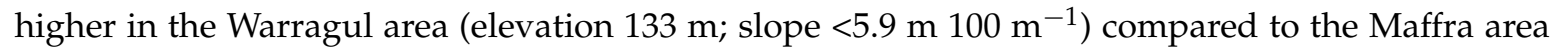

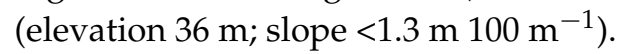

\section{Conclusions}

The results obtained in this study indicate that soil type, fertiliser P application rate and timing, and moisture variations had significant influence on soil P measurements and P speciation by NMR analysis. The lowest soil $\mathrm{P}$ concentrations were found in soil samples from sites with no recent inorganic fertiliser P inputs and this correlated well with the observed signal intensities of the NMR spectra. Soils from Maffra area which received moisture from both rainfall and boarder-check (flood) irrigation had much higher organic $\mathrm{P}$ (combined monoester $\mathrm{P}$ and diester $\mathrm{P}$ ) than those from the Warragul area. Whether this highlights the difference moisture may play in the formation of higher organic P component in soil is unclear and requires further detailed investigation. On the other hand, the soils from the Warragul area which received higher fertiliser $\mathrm{P}$ addition had much higher orthophosphate proportion (67.0\% on average) and total $\mathrm{P}\left(2059 \mathrm{mg} \mathrm{P} \mathrm{kg}{ }^{-1}\right.$ on average) than soils in the Maffra area (57.6\% and $1822 \mathrm{mg} \mathrm{P} \mathrm{kg}^{-1}$, respectively, on average) which received much less fertiliser $\mathrm{P}$ addition. Thus, highlighting the importance of application rate of fertiliser $\mathrm{P}$ in management practices applied to ensure optimum plant available $P$.

The soil type also had a major influence on soil P concentrations and speciation. On average, orthophosphate contributions were 5.5\% lower in Dermosols compared to those of Ferrosols, and even lower (9.2\%) when identical fertiliser P inputs and management strategies were employed. Even Sodosols were on average $14.7 \%$ lower in orthophosphate than Ferrosols. In contrast, the organic $P$ (combined monoester P and diester P) proportion in Sodosols was on average 5.8\% and $11.7 \%$ higher than those of Dermosols and Ferrosols, respectively. The pyrophosphate proportions were also generally higher in Sodosols than in Dermosols and Ferrosols. It is therefore recommended that more careful consideration must be given to soil type when undertaken or investigating management practices that are designed to assess and ensure optimum plant available $P$.

As only fourteen sampling sites were considered, the results reported in this study only provide a snapshot of a particular moment in time. Further sampling, in-depth monitoring and characterisation of different soils are necessary to enable more definitive links to be made between soil properties and site management variables.

Acknowledgments: The authors would like to acknowledge Monash University and Dairy Australia for providing funding for this project. The authors also wish to thank the University of Adelaide, Department of Soil and Land Systems, in particular Ms Ashlea Doolette, for providing access and expertise to ${ }^{31} \mathrm{P}$ NMR spectrometer.

Author Contributions: Samuel B. Adeloju contributed to initiation, experimental design, data interpretation, reviewing, revisions and write ups. Benjamin Webb contributed to experimental design, experimental work, data interpretation and associated write up. Ronald Smernik contributed to specialised experimental work, reviewing and interpretation.

Conflicts of Interest: The authors declare no conflict of interest. 


\section{References}

1. Holford, I. Phosphate behaviour in soils. Agric. Sci. 1989, 2, 15-21.

2. Dougherty, W.J.; Smernik, R.J.; Chittleborough, D.J. Application of spin counting to the solid-state ${ }^{31} \mathrm{P}$ NMR analysis of pasture soils with varying phosphorus content. Soil Sci. Soc. Am. J. 2005, 69, 2058-2070. [CrossRef]

3. George, T.S.; Richardson, A.E.; Hadobas, P.A.; Simpson, R.J. Characterization of transgenic Trifolium subterraneum L. Which expresses $p h y A$, releases extracellular phytase: Growth, P nutrition in laboratory media, soil. Plant Cell Environ. 2004, 27, 1351-1361. [CrossRef]

4. Sanyal, S.K.; DeDatta, S.K. Chemistry of phosphorus transformations in soil. Adv. Soil Sci. 1991, 16, 1-120.

5. Richardson, A.E.; Hadobas, P.A.; Hayes, J.E. Extracellular secretion of aspergillus phytase from arabidopsis roots enables plants to obtain phosphorus from phytate. Plant J. 2001, 25, 641-649. [CrossRef] [PubMed]

6. Dalal, R.C. Soil organic phosphorus. Adv. Agron. 1977, 29, 83-117.

7. Tunney, H.; Coulter, B.; Daly, K.; Kurz, I.; Coxon, C.; Jeffrey, D.; Mills, P.; Kiely, G.; Morgan, G. Quantification of Phosphorus Loss from Soil To Water; Teagasc Agriculture, Food Development Authority: Wexford, UK, 2000; p. 83.

8. Chen, C.R.; Condron, L.M.; Turner, B.L.; Mahieu, N.; Davis, M.R.; Xu, Z.H.; Sherlock, R.R. Mineralisation of soil orthophosphate monoesters under pine seedlings, ryegrass. Aust. J. Soil Res. 2004, 42, 189-196. [CrossRef]

9. Addiscott, T.M.; Thomas, D. Tillage, mineralization,, leaching: Phosphate. Soil Tillage Res. 2000, 53, $255-273$. [CrossRef]

10. Hansen, J.C.; Cade-Menun, B.J.; Strawn, D.G. Phosphorus speciation in manure-amended alkaline soils. J. Environ. Qual. 2004, 33, 1521-1527. [CrossRef] [PubMed]

11. McDowell, R.W.; Condron, L.M.; Stewart, I.; Cave, V. Chemical nature, diversity of phosphorus in New Zealand pasture soils using ${ }^{31} \mathrm{P}$ Nuclear Magnetic Resonance spectroscopy, sequential fractionation. Nutr. Cycl. Agroecosyst. 2005, 72, 241-254. [CrossRef]

12. Turner, B.L.; Cade-Menun, B.J.; Westermann, D.T. Organic phosphorus composition, potential bioavailability in semi-arid arable soils of the Western United States. Soil Sci. Soc. Am. J. 2003, 67, 1168-1179. [CrossRef]

13. Dyer, W.J.; Wrenshall, C.L.; Smith, G.R. The isolation of phytin from soil. Science 1940, 91, 319-320. [CrossRef] [PubMed]

14. Yoshida, R.K. Studies on organic phosphorus compounds in soil; isolation of inositol. Soil Sci. 1940, 50, 81-89. [CrossRef]

15. Turner, B.L.; Mahieu, N.; Condron, L.M. Quantification of myo-inositol hexakisphosphate in alkaline soil extracts by solution ${ }^{31}$ P NMR spectroscopy, spectral deconvolution. Soil Sci. 2003, 168, 469-478. [CrossRef]

16. Anderson, G. Assessing organic phosphorus in soils. In The Role of Phosphorus in Agriculture; Khasawneh, F.E., Sample, E.C., Kamprath, E.J., Eds.; American Society of Agronomy: Madison, WI, USA, 1980; pp. 411-431.

17. Williams, C.H.; Anderson, G. Inositol phosphates in some Australian soils. Aust. J. Soil Res. 1968, 6, 121-130. [CrossRef]

18. Smernik, R.J.; Dougherty, W.J. Identification of phytate in phosphorus-31 Nuclear Magnetic Resonance spectra: The need for spiking. Soil Sci. Soc. Am. J. 2007, 71, 1045-1050. [CrossRef]

19. Cosgrove, D.J. The chemical nature of soil organic phosphorus. Aust. J. Soil Res. 1963, 1, 203-214. [CrossRef]

20. McKercher, R.B.; Anderson, G. Content of inositol penta-, hexaphosphates in some Canadian soils. J. Soil Sci. 1968, 19, 47-55. [CrossRef]

21. Steward, J.H.; Tate, M.E. Gel chromatography of soil organic phosphorus. J. Chromatogr. 1971, 60, 75-82. [CrossRef]

22. Caldwell, A.G.; Black, C.A. Inositol hexaphosphate: I. Quantitative determination in extracts of soils, manures. Soil Sci. Soc. Am. Proc. 1958, 59, 290-293. [CrossRef]

23. Cade-Menun, B.J. Characterizing phosphorus in environmental, agricultural samples by ${ }^{31} \mathrm{P}$ Nuclear Magnetic Resonance spectroscopy. Talanta 2005, 66, 359-371. [CrossRef] [PubMed]

24. Newman, R.H.; Tate, K.R. Soil phosphorus characterization by phosphorus-31 Nuclear Magnetic Resonance. Commun. Soil Sci. Plant Anal. 1980, 11, 835-842. [CrossRef]

25. Cade-Menun, B.J.; Preston, C.M. A comparison of soil extraction procedures for ${ }^{31} \mathrm{P}$ NMR spectroscopy. Soil Sci. 1996, 161, 770-785. [CrossRef] 
26. Rheinheimer, D.S.; Anghinoni, I.; Flores, A.F. Organic, inorganic phosphorus as characterized by phosphorus-31 Nuclear Magnetic Resonance in subtropical soils under management systems. Commun. Soil Sci. Plant Anal. 2002, 33, 1853-1871. [CrossRef]

27. Cardoso, I.M.; van der Meer, P.; Oenema, O.; Janssen, B.H.; Kuyper, T.W. Analysis of phosphorus by ${ }^{31}$ P NMR in oxisols under agroforestry, conventional coffee systems in Brazil. Geoderma 2003, 112, 51-70. [CrossRef]

28. Tate, K.R.; Newman, R.H. Phosphorus fractions of a climosquence of soils in New Zealand tussock grassland. Soil Biol. Biochem. 1982, 14, 191-196. [CrossRef]

29. Gerke, J. The acquisition of phosphate by higher plants: Effect of carboxylate release by the roots. A critical review. J. Plant Nutr. Soil Sci. 2015, 178, 351-364. [CrossRef]

30. Braithwaite, G.D. Calcium, phosphorus metabolism in ruminants with special reference to parturient paresis. J. Dairy Res. 1976, 43, 501-520. [CrossRef] [PubMed]

31. Haynes, R.J.; Williams, P.H. Nutrient cycling, soil fertility in the grazed pasture ecosystem. Adv. Agron. 1993, 49, 119-199.

32. Rowarth, J.S.; Gillingham, A.G.; Tillman, R.W.; Syers, J.K. Effects of season, fertiliser rate on phosphorus concentrations in pasture, sheep faeces in hill country. N. Z. J. Agric. Res. 1988, 31, 187-193. [CrossRef]

33. Bol, R.; Amelung, W.; Haumaier, L. Phosphorus-31-Nuclear Magnetic Resonance spectroscopy to trace organic dung phosphorus in a temperate grassland soil. J. Plant Nutr. Soil Sci. 2006, 169, 69-75. [CrossRef]

34. Aarons, S.R.; O'Connor, C.R.; Gourley, C.J.P. Dung decomposition in temperate dairy pastures. I. Changes in soil chemical properties. Aust. J. Soil Res. 2004, 42, 107-114. [CrossRef]

35. Dickinson, C.H.; Craig, G. Effects of water on the decomposition, release of nutrients from cow pats. New Phytol. 1990, 115, 139-147. [CrossRef]

36. Dickinson, C.H.; Underhay, V.S.H.; Ross, V. Effects of season, soil fauna, water content on the decomposition of cattle dung pats. New Phytol. 1981, 88, 129-141. [CrossRef]

37. Nash, D.M.; Clemow, L.M. Paddock to Farm Scaling of Nutrient Transfer Processes: Final Report to Dairy Australia; Department of Primary Industries: Ellinbank, Australia, 2003.

38. Nash, D.; Webb, B.; Hannah, M.; Adeloju, S.; Toifl, M.; Barlow, K.; Robertson, F.; Roddick, F.; Porter, N. Changes in nitrogen, phosphorus concentrations in soil, soil water, surface run-off following grading of irrigation bays used for intensive grazing. Soil Use Manag. 2007, 23, 374-383. [CrossRef]

39. Isbell, R.F. Australian Soil Classification; CSIRO Publishing: Melbourne, Australia, 2002.

40. Sargeant, I.; Imhof, M.; Lourey, R.; Martin, J.; Paul, R. Major Agricultural Soils of West Gippsland Soil Pit Field Day Handbook; Department of Natural Resources, Environment: Melbourne, Australia, 1997; p. 47.

41. Sargeant, I.; Imhov, M. Major Agricultural Soils of the Maffra Region; Department of Natural Resources, Environment: Maffra, Australia, 2000.

42. Rayment, G.E.; Higginson, F.R. Australian Laboratory Handbook of Soil, Water Chemical Methods; Inkata Press: Melbourne, Australia, 1992; p. 330.

43. Murphy, J.; Riley, J.P. A modified single solution method for the determination of phosphate in natural waters. Anal. Chim. Acta 1962, 27, 31-36. [CrossRef]

44. Doolette, A.L.; Smernik, R.J.; Dougherty, W.J. Spiking improved solution phosphorus-31 Nuclear Magnetic Resonance identification of soil phosphorus compounds. Soil Sci. Soc. Am. 2009, 73, 919-927. [CrossRef]

45. Turner, B.L. Soil organic phosphorus in tropical forests: An assessment of the NaOH-EDTA extraction procedure for quantitative analysis by solution 31 P NMR spectroscopy. Eur. J. Soil Sci. 2008, 59, 453-466. [CrossRef]

46. Turner, B.L.; Richardson, A.E. Identification of scyllo-inositol phosphates in soil by solution phosphorus-31 Nuclear Magnetic Resonance spectroscopy. Soil Sci. Soc. Am. J. 2004, 68, 802-808. [CrossRef]

47. McDowell, R.W.; Stewart, I. The phosphorus composition of contrasting soils in pastoral, native, forest management in Otago, New Zealand: Sequential extraction, ${ }^{31} \mathrm{P}$ NMR. Geoderma 2006, 130, 176-189. [CrossRef]

48. Turner, B.L.; Mahieu, N.; Condron, L.M. The phosphorus composition of temperate pasture soils determined by $\mathrm{NaOH}$-EDTA extraction, solution ${ }^{31} \mathrm{P}$ NMR spectroscopy. Org. Geochem. 2003, 34, 1199-1210. [CrossRef]

49. Hawkes, G.E.; Powlson, D.S.; Randall, E.W.; Tate, K.R. A ${ }^{31}$ P Nuclear Magnetic Resonance study of the phosphorus species in alkali extracts of soils from long-term field experiments. J. Soil Sci. 1984, 35, 35-45. [CrossRef] 
50. Barrow, N.J. Evaluation, utilisation of residual phosphorus in soils. In The Role of Phosphorus in Agriculture; Khasawneh, F.E., Sample, E.C., Kamprath, E.J., Eds.; American Society of Agronomy: Madison, WI, USA, 1980.

51. Barrow, N.J. Surface reactions of phosphate in soil. Agric. Sci. 1989, 2, 33-38.

52. Condron, L.M.; Goh, K.M.; Newman, R.H. Nature, distribution of soil phosphorus as revealed by a sequential extraction method followed by phosphorus-31 Nuclear Magnetic Resonance analysis. J. Soil Sci. 1985, 36, 199-207. [CrossRef]

53. Makarov, M.I.; Haumaier, L.; Zech, W. The nature, origins of diester phosphates in soils: A ${ }^{31}$ P NMR study. Biol. Fertil. Soils 2002, 35, 136-146.

54. Pant, H. Identification of soil organic phosphorus by ${ }^{31} \mathrm{P}$ Nuclear Magnetic Resonance spectroscopy. Commun. Soil Sci. Plant Anal. 1999, 30, 757. [CrossRef]

55. Robinson, J.S.; Johnston, C.T.; Reddy, K.R. Combined chemical, ${ }^{31} \mathrm{P}$ NMR spectroscopic analysis of phosphorus in wetland organic soils. Soil Sci. 1998, 163, 705-713. [CrossRef]

56. Bureau of Meteorology. Available online: http://www.bom.gov.au (accessed on 22 January 2016).

57. Trasar-Cepeda, M.C.; Gil-Sotres, F.; Zech, W.; Alt, H.G. Chemical, spectral analysis of organic phosphorus forms in acid, high organic matter soils in Galicia (N.W. Spain). Sci. Total Environ. 1989, 81, 429-436. [CrossRef]

58. Gil-Sotres, F. Characterization of phosphorus fractions in surface horizons of soils from galicia (N.W. Spain) by phosphorus-31 NMR spectroscopy. Soil Biol. Biochem. 1990, 22, 75-79. [CrossRef]

59. Cox, J.W.; McFarlane, D.J. The causes of waterlogging in shallow soils, their drainage in south western australia. J. Hydrol. 1995, 167, 175-194. [CrossRef]

60. Dougherty, W.J.; Fleming, N.K.; Cox, J.W.; Chittleborough, D.J. Phosphorus transfer in surface runoff from intensive pasture systems at various scales: A review. J. Environ. Qual. 2004, 33, 1973-1988. [CrossRef] [PubMed]

61. Nash, D.M.; Murdoch, C. Phosphorus in runoff from a fertile dairy pasture. Aust. J. Soil Res. 1997, 35, 419-429. [CrossRef]

62. Fleming, N.K.; Cox, J.W. Carbon, phosphorus losses from dairy pasture in South Australia. Aust. J. Soil Res. 2001, 39, 969-978. [CrossRef]

(C) 2016 by the authors; licensee MDPI, Basel, Switzerland. This article is an open access article distributed under the terms and conditions of the Creative Commons by Attribution (CC-BY) license (http://creativecommons.org/licenses/by/4.0/). 